\title{
PLANEJAMENTO RACIONAL DE FÁRMACOS BASEADO EM PRODUTOS NATURAIS
}

Carlos Alberto Montanari ${ }^{1}$

Departamento de Química, Universidade Federal de Minas Gerais, Campus da Pampulha, 31270-901 Belo Horizonte - MG

Vanderlan da S. Bolzani ${ }^{2}$

Instituto de Química, Universidade Estadual Paulista, CP 355, 14800-900 Araraquara - SP

Recebido em 4/1/00; aceito em 3/10/00

DRUG DESIGN BASED ON NATURAL PRODUCTS. In the area of drug discovery, natural products represent a myriad of templates for new lead discovery. It is, however, most unlikely that the bioactive principle itself shall become a drug; it is much more likely that a medicinal chemistry project needs to be initiated as soon the potency or selectivity or specificity of the new natural product candidate has been disclosed. Brazil has an enormous biodiversity where just a few has been disclosed. Nevertheless, it urges to initiate a joint collaboration in order to circumvent a major breakdown linking between natural products and medicinal chemistry in this country. This paper is intended to encourage people to follow up one of the most pushing forward enterprise that needs to be settled: the pharmaceutical industry.

Keywords: natural products; medicinal chemistry; pharmaceutical industry.

\section{INTRODUÇÃO}

Os metabólitos secundários produzidos por plantas, melhor conceituados, segundo Gottlieb ${ }^{1}$ como metabólitos especiais, tiveram um papel fundamental no desenvolvimento da química orgânica sintética moderna. Historicamente, o desenvolvimento da química orgânica ocorreu paralelamente ao estudo de plantas, principalmente a partir do século XIX, quando foram registrados os primeiros estudos sobre plantas, com base científica. Isso resultou no isolamento de alguns princípios ativos de plantas, já então conhecidas como medicinais. Desses estudos foram obtidas algumas substâncias que se consagraram como príncipios ativos eficazes, e que até hoje, ainda são muito empregados no tratamento de certas doenças, a exemplo de morfina, quinina, cânfora, e cocaína, Figura $1^{2,3}$.

A natureza, de forma geral, tem produzido a maioria das substâncias orgânicas conhecidas. Entretanto, é o Reino Vegetal que tem contribuído de forma mais significativa para o fornecimento de substâncias úteis ao tratamento de doenças que acometem os seres humanos ${ }^{4}$. A fantástica variedade e complexidade de metabólitos especiais biossintetizados pelas plantas teriam-se formado e evoluído, como mecanismo de defesa desses vegetais às condições ambientais ricas em microrganismos, insetos, animais e também às condições de adaptação e regulação ${ }^{5}$. No contexto da evolução das plantas terrestres, estima-se, atualmente, que cerca de 500.000 espécies ocupam todo o planeta, sendo que, 50\% (250.000) são constituídas pelas angiospermas ${ }^{6}$. No auge desse processo evolutivo, as angiospermas alcançaram, sem dúvida, um desenvolvimento ímpar, dada a ocorrência de micromoléculas distintas e complexas, com vários centros estereogênicos; possivelmente, devido a essas características, sejam-lhes atribuídas inúmeras finalidades alelopáticas e biológicas ${ }^{7}$. Desta forma, as plantas constituem-se num enorme laboratório de síntese orgânica, fruto de milhões de anos de evolução e adaptação sobre a terra.

É importante ressaltar também que, devido ao fantástico desenvolvimento de técnicas analíticas de separação e elucidação estrutural, nas últimas três décadas - mais recentemente de instrumentos analíticos hifenados, conhecem-se cerca de 50.000

\footnotetext{
1 Email: montana@dedalus.lcc.ufmg.br
}

2 Email: bolzaniv@iq.unesp.br
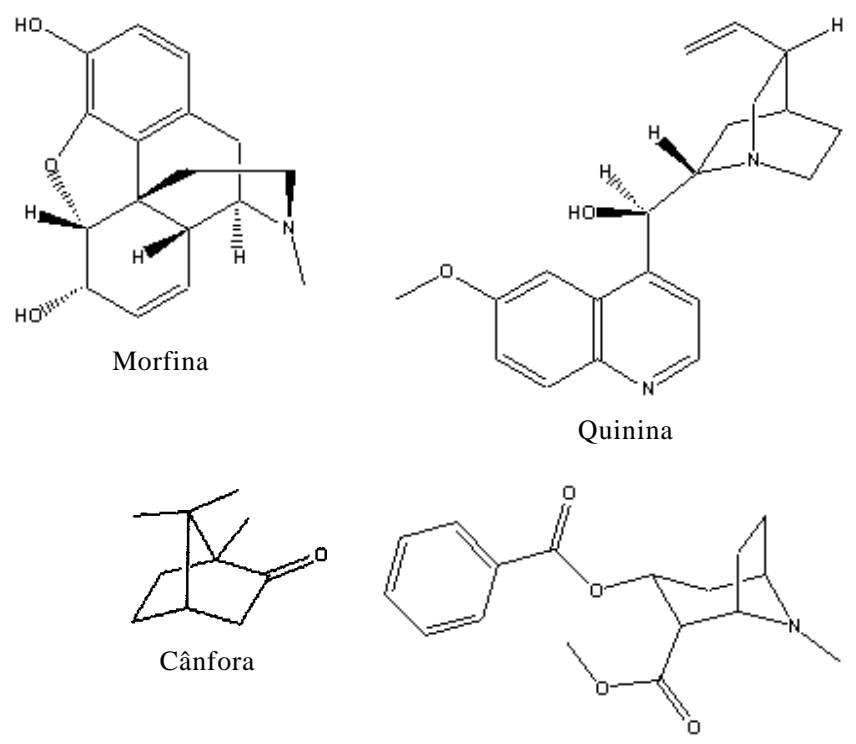

Cocaína

Figura 1. Estruturas químicas de alguns princípios ativos isolados de plantas.

metabólitos secundários isolados de angiospermas, muitos desses ainda sem qualquer avaliação com relação ao seu potencial farmacológico. Devido a tais constatações, os produtos naturais e derivados foram, e continuam sendo, notoriamente, de importância crucial em determinados setores de uma sociedade moderna, mesmo considerando-se o grande número de produtos produzidos por síntese.

No século XX, o surgimento dos antibióticos produzidos por fermentação microbiana aliado ao desenvolvimento marcante de fármacos sintéticos produzidos pela indústria farmacêutica, logo depois da Grande Guerra, foram causas marcantes no declínio do uso de plantas medicinais e consequentemente, no investimento em fármacos de origem vegetal. Nas últimas décadas, uma importante mudança no paradigma das sociedades ocidentais fez com que os produtos de plantas passassem novamente a ocupar papel de destaque por grandes contigentes das populações de países desenvolvidos e em desenvolvimento. 
Detentores de um mercado extremamente lucrativo, os fitofármacos, como por exemplo ginkgo, kava pironas, ginseng, erva de são joão, etc, reacenderam o interesse da indústria farmacêutica pelos produtos de origem vegetal. Por volta de 1990 , estimou-se que cerca de $80 \%$ da população mundial procuravam nas plantas a fonte principal de medicamentos ${ }^{8}$. Está comprovado hoje, que grande parte da população mundial, principalmente aquelas de países em desenvolvimento usa como medicamentos extratos ou porções oriundas de plantas.

A indústria farmacêutica motivada, em parte, pela descoberta de quimioterápicos eficazes como vimblastina (Velban ${ }^{\circledR}$ ), vincristina $\left(\right.$ Oncovin $\left.{ }^{\circledR}\right)$, podofilotoxina e os análogos etoposídeo (VP-16-213; Vepeside ${ }^{\circledR}$ ) e teniposídeo (VM-26; Vumon ${ }^{\circledR}$ ), camptotecina e taxol (plaxitaxel; Taxol ${ }^{\circledR}$ ), Figura 2, reativou o interesse pelos medicamentos de origem vegetal, principalmente pela busca de substâncias com estruturas moleculares complexas, praticamente impossíveis de serem obtidas por um processo sintético de custo racional. A constatação desse fato é que a síntese comercial do taxol, na realidade é uma semi-síntese, cuja matéria prima é bacatina III $^{9}$ ou cefalomanina ${ }^{10}$, ambas com o esqueleto taxano e o anel oxietano completamente formados.

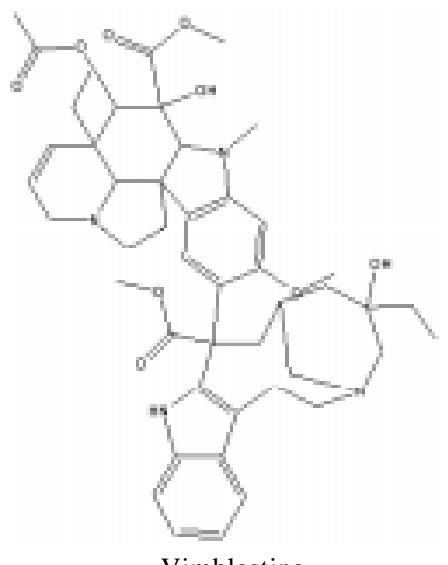

Vimblastina

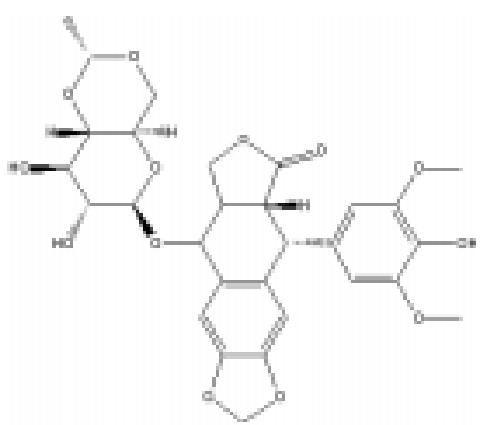

Etoposídeo

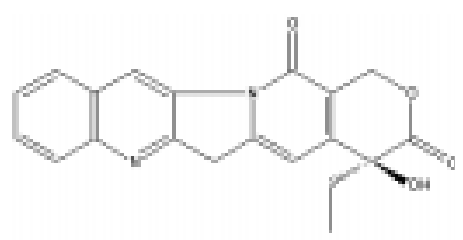

Camptotecina
Mais fantástico ainda, é o acúmulo de substâncias enantiomericamente puras, pelas plantas. Todo químico sintético sabe o desafio que é produzir uma síntese assimétrica no laboratório, e que a natureza realiza de maneira excepcional. A preocupação da indústria farmacêutica com produtos quirais intensificou-se depois dos graves efeitos causados por drogas como a talidomida, por exemplo. Sabe-se hoje que a teratogênese fetal é decorrente da ação do enantiômero (-). O mercado de cardivasculares, antibióticos, hormônios, vitaminas, antiinflamatórios e anticancerígenos enantioméricos entre 1993 e 1994 girava em torno de $27 \%$. Este mercado "explodiu" em 1994 e o faturamento de produtos quirais produzidos a partir de plantas, só nesse ano, alcançou 45.2 bilhões de dólares ${ }^{11,12}$.

Fundamentada nesse princípio, a indústria farmacêutica vem aplicando grandes investimentos em pesquisas de bioprospeção, mesmo tendo em conta que a pesquisa de novos fármacos é um mercado de alto risco. De acordo com a Pharmaceutical Research and Manufactures of America (PhRMA) dentre 5.000-10.000 candidatos a fármacos, apenas um passa para fase de testes pré-clínicos e clínicos e é submetido a aprovação do FDA para comercialização. Levando em consideração o custo

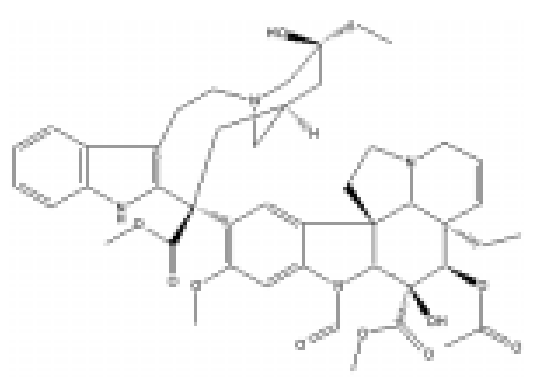

Vimcristina

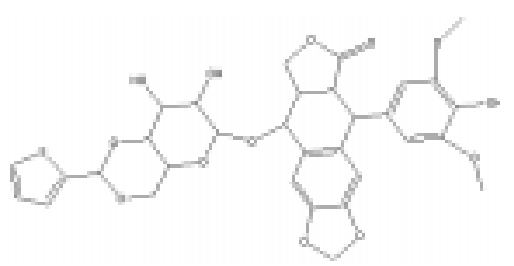

Teniposídeo

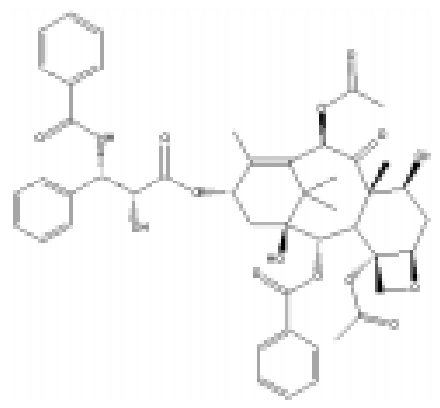

Taxol

Figura 2. Quimioterápicos de origem vegetal de interesse da indústria farmacêutica. 
do investimento, e o retorno econômico de um produto farmacêutico, a indústria transnacional tem canalizado gigantescos investimentos em doenças como AIDS, mal de Alzheimer, câncer, depressão, diabetes, doenças cardíacas, derrame e osteoporose, principalmente ${ }^{13}$

Com objetivos muito bem definidos, a indústria farmacêutica não despreza o potencial que as plantas possuem em fornecer substâncias novas. Entretanto, para otimizar a busca por princípios bioativos de maneira racional, por volta dos anos 80 , a indústria farmacêutica redirecionou todo o processo de seleção de produtos bioativos, no que se denominou de "busca racional de drogas" pelo uso de fracionamento guiado por bioensaios específicos para enzimas, receptores, DNA, etc, e também motivado pelo conhecimento de mecanismo de ação de novas substâncias químicas bioativas [bioactives new chemical entities (BIONCEs) $]^{14}$. Dentro desse modelo, uma indústria farmacêutica de grande porte selecionava em média, cerca de 5.000 substâncias por ano. Nos anos 90, com advento da química combinatória, ${ }^{15}$, ${ }^{15 a}$ banco de germoplasma ${ }^{16}$ e bioensaios em larga escala ${ }^{17}$ [high-throughput screening (HTS)], os programas de descoberta de novos fármacos mudaram radicalmente. Hoje, um programa de HTS pode testar o mesmo número de substâncias (ou mais) em apenas um dia. Usando a química combinatória como ferramenta, a química medicinal aumentou em centenas de vezes a produtividade de BIONCEs. De acordo com Salvatore Forenza, Diretor executivo do Lead DiscoveryBristol-Myers Squib Pharmaceutical Research Institute, a química medicinal é hoje, responsável pela produção de todas as classes de substâncias, em média de 50-100 substâncias por semana. ${ }^{18}$

A descoberta de produtos naturais bioativos constitui, portanto, não apenas uma necessidade de sua identificação própria mas, principalmente, contribui para o conhecimento de NCEs; que podem ser usadas como matrizes para a descoberta de novos fármacos. A avaliação e confirmação iniciais da bioatividade de uma NCE frente a um determinado alvo (receptor, enzima, etc) não caracterizam que esse princípio ativo torna-se-á um novo fármaco. Essa NCE não será, necessariamente, uma substância matriz e, certamente não será um fármaco. Isso significa que as propriedades de absorção e distribuição terão importâncias semelhantes às afinidades eventualmente apresentadas pelo ligante. É muito provável, portanto, que um produto natural de uma espécie vegetal, incluído nessa categoria, terá necessariamente de se adequar a um projeto em química medicinal para planejar, racionalmente, as modificações moleculares que serão realizadas na estrutura do protótipo.

A respeito de produtos naturais de espécies vegetais visando novos fármacos, a indústria farmacêutica considera que só um programa tipo "produção de NCEs via HTS" poderia selecionar substâncias bioativas em tempo e custo hábeis para sua viabilização como fármaco e posterior comercialização. A grande contradição para o "sucesso absoluto" de um programa dessa natureza com plantas é que, se por um lado os países desenvolvidos detêm a tecnologia, são os países em desenvolvimento que detêm praticamente toda biodiversidade da terra. E mais, são as indústrias transnacionais as responsáveis pela maioria das pesquisas envolvendo novos fármacos.

No Brasil, já no início de um novo século, as pesquisas com plantas ainda estão muito centradas no âmbito da Universidade e Institutos de Pesquisa onde se desenvolve basicamente a fitoquímica tradicional. Muito embora já existam vários grupos nacionais envolvidos com a busca de princípios bioativos de plantas, essa pesquisa é fundamentalmente acadêmica. Apesar disso, a academia poderá contribuir de forma decisiva para o descobrimento de NCEs. Talvez, esse seja o seu papel exatamente porque essa etapa da pesquisa demanda muito tempo e pode envolver a qualificação de recursos humanos.

Considerando-se que um programa de descoberta de novos fármacos é um processo muito longo, complexo e de alto custo; considerando-se ainda que o processo envolve duas etapas distintas a fase de descoberta e a de desenvolvimento e comercialização; não há dúvidas que a competência científica nacional está qualificada para atuar na primeira fase desse processo, com sucesso. E mais, o Brasil sendo um país detentor de uma biodiversidade fantástica, abrigando o maior repositório de angiospermas do planeta, tem em princípio, as condições básicas para se começar a estruturar um programa nacional de bioprospeção em busca de NCEs.

Em se tratando de um produto natural, a NCE conterá, provavelmente, uma estrutura química muito complexa. A sua modificação não constitui, portanto, tarefa trivial. Entretanto, a identificação de grupos farmacofóricos presentes na estrutura matriz será de fundamental importância para que as modificações moleculares sejam realizadas de forma produtiva. Um procedimento para modificar a NCE, neste estágio, pode ser pela exclusão de algumas subunidades fragmentais com o intuito de se determinar quais são as partes essenciais e quais são desnecessárias. Talvez, o exemplo clássico da importância da identificação farmacofórica seja encontrado em moléculas como a morfina, codeína e heroína, Figura $3^{19}$. Portanto, apenas uma parte de uma molécula complexa poderá elicitar uma resposta biológica e, muitas vezes, pouco potente. O exemplo mostrado na Figura 3, entretanto, mostra que a atividade pode ser modificada e também pode ter sua potência aumentada (o farmacóforo está identificado em negrito). Por exemplo, a exclusão do oxigênio do anel hidrofurânico de $\left(1, \mathrm{R}=\mathrm{R}^{1}=\mathrm{H}\right.$, morfina) resulta no morfinano $(2, \mathrm{R}=\mathrm{H})$. O seu análogo hidroxilado $(2, \mathrm{R}=$ $\mathrm{OH}$, levorfanol) é 3-4 vezes mais potente do que a morfina, embora ainda retenha propriedades de vício. A pentazocina (3, $\mathrm{R}=\mathrm{CH} 2-\mathrm{CH}=\mathrm{C}\left(\mathrm{CH}_{3}\right)_{2}$ também é um análogo com menor propriedade de vício. Mesmo análogos aciclícos são ativos. O dextropropoxifeno, $\left(4\right.$, Darvon $\left.^{\circledR}\right)$ apresenta de metade até dois terços da atividade da codeína $\left(1, \mathrm{R}=\mathrm{CH}_{3}, \mathrm{R}^{1}=\mathrm{H}\right)$. Neste caso, admite-se que seja uma relação entre a conformação farmacofórica e o farmacóforo da morfina.

Em alguns casos, entretanto, o aumento da complexidade e/ ou da rigidez pode resultar no aumento da potência. Por exemplo, a etorfina, Figura 3 (5), que tem uma ponte de dois átomos de carbono e um substituinte não localizado na subunidade da morfina é cerca de 1000 vezes mais potente do que a morfina e, por isso, tem uso em medicina veterinária para imobilizar grandes animais.

É preciso ressaltar ainda que a simplificação molecular da estrutura do produto natural, após a identificação do farmacóforo, não resulta, necessariamente em substâncias bioativas. Talvez um exemplo típico seja o da artemisinina. 1,2,4Trioxanos simplificados como os espiroalquil trioxanos, Figura 4, são de três vezes menos potentes até equipotentes à artemisinina contra Plasmodium berghei sensível a cloroquina ${ }^{20}$.

\section{DISCUSSÃO}

A química combinatória, ainda em plena fase de consolidação, poderá se tornar o ouro da indústria farmacêutica do próximo milênio. Com a disponibilização de ensaios biológicos específicos, eficientes e rápidos, os ensaios aleatórios sem qualquer intelectualização vêm sendo substituídos dia a dia nas pesquisas em busca de NCEs. Os bioensaios guiados por semelhanças estruturais e/ou interação NCE/receptor constituíram uma verdadeira revolução na busca de princípios bioativos (como no caso do AZT, por exemplo). Os estudos do metabolismo de drogas ${ }^{21}$, as observações clínicas também são ferramentas poderosas na descoberta racional de matrizes de NCEs.

A aquisição e informatização de grandes coleções de compostos químicos estabeleceram um novo paradigma no conceito de diversidade química ${ }^{15}$. Uma coleção de compostos químicos de elevada diversidade química é, naturalmente, muito cara, mas ela oferece um sem-número de diversidade molecular disponível 


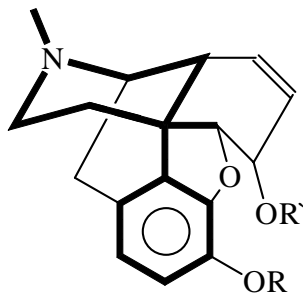

(1)

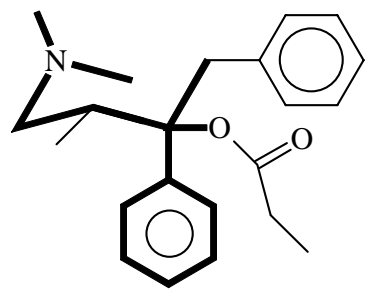

(4)

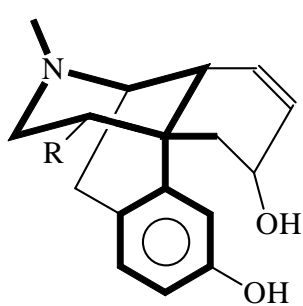

(2)

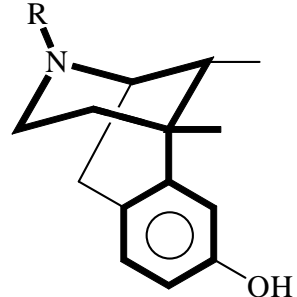

(3)

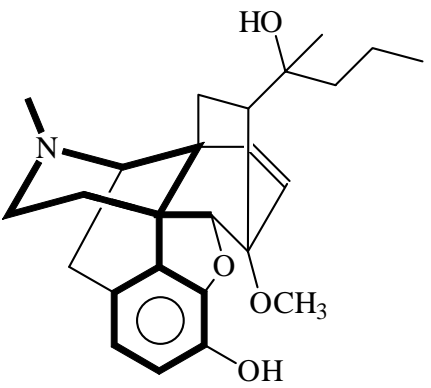

(5)

Figura 3. Exemplos de modificações moleculares que simplificam a estrutura, mas mantêm a atividade farmacológica (1-4) e de incremento estrutural que aumenta a potência (5).

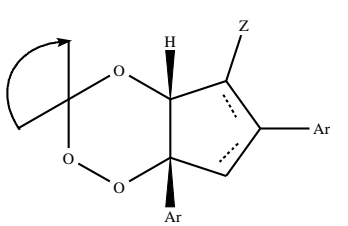

$\mathrm{Ar}=4-\mathrm{CH}_{3} \mathrm{PH}, \mathrm{Z}=\mathrm{OH}, \mathrm{OCH}_{2} \mathrm{O}\left(\mathrm{CH}_{2}\right)_{2} \mathrm{OMe}$ $\mathrm{Ar}=\mathrm{Ph}, \mathrm{Z}=\mathrm{H}$, OEt

Figura 4. 1,2,4-trioxanos simplificados e artemisinina.

para uso. Por outro lado, os ensaios biológicos automatizados, HTS, constituem uma realidade cada dia mais eficaz para a triagem biológica de milhares de compostos frente a uma miríade de sistemas biológicos. No Brasil, no estágio em que esse processo se encontra, faz-se necessário e urgente a obtenção do perfil químico e biológico das espécies de plantas brasileiras, seja por seleção aleatória, seja por metodologia racional como dados fitoquímicos e/ou quimiotaxonômicos, antes de se iniciar qualquer programa mais sofisticado como por exemplo, HTS, que identificará as possíveis $\mathrm{NCEs}^{14,15}$. O uso de métodos em derreplicação, HPLC/PDA ou HPLC/MS, associados a bancos de moléculas armazenados em computadores contendo algoritmos de reconhecimento molecular são essenciais para a redução da dimensionalidade espacial da diversidade química de interesse a um determinado alvo biológico 22 .

$\mathrm{Na}$ eventualidade do extrato "sobreviver" à derreplicação, o interesse por uma colaboração pluridisciplinar precisa ser engendrado para (i) isolar e identificar o principio ativo; (ii) estabelecer as condições necessárias para o crescimento e manutenção de alvos biológicos em meios químicos apropriados; (iii) guiar os passos da separação através de ensaios biológicos; (iv) empregar técnicas espectroscópicas e químicas; (v) estudar as relações entre a estrutura química e a atividade farmacológica.

Dentro desse contexto, o projeto em química medicinal deve ser abordado.

O melhor composto, ou seja aquele que apresentar efeito dose-resposta in vitro na ordem de nanomolar (dependendo, obviamente, do alvo biológico), vai para avaliação toxicológica. Naturalmente, não será escolhido apenas um composto mas, é aconselhável que vários compostos sejam avaliados simultaneamente. Qualquer efeito tóxico, mesmo em doses elevadas, pode resultar no término do interesse por um composto bioativo. Nesse instante, os candidatos múltiplos são avaliados.

\section{Planejamento Racional}

Apesar da existência de métodos alternativos na busca de caminhos para minorar ou acabar com as doenças que afetam o ser humano como, por exemplo, a terapia gênica ${ }^{23}$, não há dúvidas que o planejamento racional de NCEs constitui uma ferramenta importante. Entretanto, há várias complicações que precisam ser avaliadas cuidadosamente dentro do método científico que norteia a química medicinal. Os análogos devem apresentar o mesmo modo de ação mas isso nem sempre é estabelecido ${ }^{24}$. As modificações moleculares isostéricas são muito significativas e precisam ser consideradas quando da modificação da estrutura ${ }^{25}$. Entretanto, os efeitos previsíveis nas atividades farmacológicas não são facilmente implementados quando do planejamento. A conformação bioativa precisa ser conhecida para que as restrições conformacionais sejam impostas durante o processo de modelagem molecular ${ }^{26}$. Naturalmente, o planejamento baseado na estrutura do receptor pode trazer melhores informações dessa natureza ${ }^{27}$. Mas, no planejamento baseado apenas na estrutura do ligante ${ }^{28}$, que ainda constitui a grande maioria dos casos, a conformação farmacofórica não é conhecida. O uso da conformação como quarta dimensão em estudos de QSAR 3D pode ser empregado nesses $\operatorname{casos}^{29}$. Entretanto, é importante salientar que à semelhança de muitos agentes antiistamínicos aquirais ${ }^{15}$, a conformação pode não ser um requisito importante. De qualquer forma, o conceito da "chave-e-fechadura"15, 30 quando aliado à interação flexível deve fazer parte das restrições conformacionais ${ }^{26}$. Os efeitos alostéricos estabelecem que a atividade biológica não é uma simples função da afinidade na interação ${ }^{31}$. As interações precisam ser descritas através de suas entalpias e entropias ${ }^{32}$. 
Inicialmente, as NCEs têm que ser avaliadas em modelos in vitro $^{33}$. Esse requisito é muito importante por vários fatores. Talvez ainda não seja o caso em países como o Brasil, mas a redução do número de animais a ser usados nesses ensaios é drástica. É claro que, aliado a isso está o custo, que não é baixo no caso do uso indiscriminado de animais ${ }^{34}$. É importante ressaltar, por outro lado, que ensaios in vitro também podem fornecer informações complexas sobre mecanismos moleculares ${ }^{34}$. Não obstante, as investigações farmacocinéticas não são estudadas nessa fase para todos os compostos. Apenas alguns poucos o serão. Portanto, os efeitos colaterais não são observados. É bom salientar que muitas das drogas novas falham, entretanto, na fase farmacocinética.

Um outro aspecto importante que tem sido motivo de grande engano pela comunidade científica é não entender que planejamento do ligante não significa planejamento do fármaco. Os estudos farmacocinéticos precisam ser incluídos nas fases iniciais do processo de otimização. A avaliação dos efeitos de absorção, distribuição, metabolismo e excreção, ADME, precisa ser realizada em fase pré-clínica.

É muito comum durante o processo de otimização que a potência seja a única propriedade a ser avaliada. Por isso, também é muito comum que o insucesso advenha desse direcionamento. Parâmetros como solubilidade, biodisponibilidade e permeabilidade podem ser considerados, principalmente, no que diz respeito ao uso oral de medicamentos. Por isso, atualmente, tem-se considerado inicialmente a eventual descoberta de uma nova substância química, NCE, que é preferivelmente referenciada como um ligante. A sua ação farmacológica será tão importante quanto os fenômenos de absorção e distribuição que são analisados em fases farmacocinéticas do descobrimento de fármacos ${ }^{35}$. Com base nesses conceitos, Lipinsky ${ }^{36}$ formulou recentemente aquilo que tem sido difundido como sua regra. Ela estabelece que uma NCE não será uma boa candidata para descobrimento e desenvolvimento quando contiver massa molar acima de 500 u.m.a., coeficiente de partição, $\log \mathrm{P}$, acima de 5 , número de átomos de $\mathrm{N}+\mathrm{O}$ maior do que 10 e número de átomos capazes de participar em doações de ligações de hidrogênio maior do que 5. Embora trate-se de uma regra que ainda precisa demonstrar sua utilidade, NCEs que falham podem apresentar essas características conjunta ou separadamente! No início de um projeto em química medicinal deve-se calcular esses descritores como forma de avaliar previamente a ADME. Alguns programas de computador, como o TSAR ${ }^{37}$ já apresentam como facilidade o cálculo inicial dessas propriedades.

Finalmente, poder-se-ia perguntar: Os ligantes podem ser planejados racionalmente? Aparentemente, a resposta para essa pergunta é sim. E, duas formas básicas de planejamento racional podem ser empregadas: (i) planejamento racional baseado em estrutura do ligante e (ii) planejamento racional baseado em estrutura do receptor. Há inúmeros métodos de planejamento racional que são considerados robustos e de uso corrente tanto em universidades como em indústrias farmacêuticas. A lista a seguir é apenas sugestiva e, naturalmente está longe de ser exaustiva. Mas, de qualquer forma, é preciso enfatizar que antes de ser sintetizado ou modificado, o ligante precisa ser planejado. Por exemplo:

(i) SAR através de NMR; $;^{38}$

(ii) $\mathrm{LUDI}^{39}$

(iii) DOCK; ${ }^{40}$

(iv) GRID; ${ }^{41}$

(v) GROW; ${ }^{42}$

(vi) $3 \mathrm{D}$ QSAR, ${ }^{43} 4 \mathrm{D} \mathrm{QSAR},{ }^{44} \mathrm{NN},{ }^{45} \mathrm{GOLPE},{ }^{46} \mathrm{PCA}^{47}$

\section{Custos}

O número de drogas introduzidas na terapia humana desde a década de 1970 está na magnitude de 1000. Na década de 19701979 foram 60-70 NCEs por ano; 1980-1989, aproximadamente
50, 1990-1995, 38-44, 1996 - 52, 1997 - 56, 1998 praticamente o mesmo de $1997 .^{48}$ Pode ser observado que há um ligeiro declínio no número de NCEs nesse período. Vários fatores têm contribuído para isso. Dentre eles, as especificidades (ou seletividades) nas interações com receptores. Por exemplo, a Organização Mundial da Saúde, OMS, tem recomendado que drogas quirais, eutômeros e distômeros, precisam ser separadas e comercializadas individualmente. Os custos das pesquisas têm crescido drasticamente. Embora seja matéria de disputa, a indústria farmacêutica norte-americana tem, insistentemente, dito que os custos são da ordem de 300-350 milhões de dólares por novo fármaco!

\section{Indústria, Universidade ou Rede de Cooperação?}

O caráter pluridisciplinar da química medicinal está bem estabelecido: a química, biologia molecular, bioquímica, farmacologia, toxicologia, medicina e etc., são alguns exemplos das interfaces que fazem da química medicinal uma ciência sem nome $e^{14,49}$.

A indústria farmacêutica brasileira precisa ser viabilizada através de grandes investimentos em pesquisa básica e desenvolvimento. Na situação atual, cerca de $85 \%$ das indústrias transnacionais sediadas no Brasil praticam toda pesquisa de descoberta e desenvolvimento em seus países de origem. A universidade brasileira tem competência instalada na área de produtos naturais, síntese química e química medicinal associadas às diversas interfaces acima mencionadas.

Parece razoável assumir, entretanto, que o estabelecimento de redes cooperativas será a próxima etapa a alcançar. As suas implementações precisam (i) partir da química clássica para a síntese automatizada de coleções combinatórias de compostos. A química combinatória virtual ${ }^{15}$ constitui uma ferramenta importante nesse estágio de descobrimento, Figura 5. O impacto da síntese combinatória está no descobrimento da substância matriz e, posteriormente, na otimização da substância matriz que propiciará a seleção da droga potencial ${ }^{14}$, 50; (ii) partir do planejamento clássico para os métodos baseados em estruturas e ajudados por computador, CAMD; (iii) partir dos ensaios in vivo e in vitro em pequena escala para os métodos automatizados de ensaios em batelada, HTS; (iv) cooperar e unir esforços para a resolução de problemas comuns.

A cada ano, há perda de recursos humanos e financeiros: a descoberta de NCEs fica, naturalmente, postergada ou então o tempo de restrição à propriedade intelectual exaure-se.

A proteção por patentes é uma importante questão. A obrigação em compartilhar os direitos de propriedade intelectual, IPR, para um princípio ativo é, em geral, bem aceita. Mas, infelizmente, não o é para compostos matrizes e seus análogos modificados racionalmente.

Há a necessidade de colaboração prévia com especialistas botânico-taxonômistas, únicos com autoridade para identificar e/ou classificar plantas e opinar sobre populações ou indivíduos em extinção, fundamentais na coleta de amostras para posterior avaliação.

Há uma estimativa da existência de cerca de 500.000 espécies neste planeta. Quanto tempo é necessário para obter um composto matriz? Seis meses até dois anos? E o seu custo? Além disso, as plantas precisam ser coletadas no mesmo estágio de seus ciclos de vida, na mesma estação e no mesmo local. E a produção de metabólitos secundários por culturas de tecidos de origem em plantas, constituir-se-á na próxima fronteira?

Os primeiros testes clínicos são determinantes para a avaliação da nova droga potencial. Portanto, quanto antes chegar-se a esse estágio melhor. Para isso, pode-se descobrir várias drogas candidatas em paralelo e em seu estágio de desenvolvimento, planejar cuidadosamente os experimentos em fase II.

Para alcançar o sucesso nesse contexto, o tamanho (número de colaboradores), suas competências, a motivação e a flexibilidade da cooperação são requisitos fundamentais. Associado a isso está o planejamento de estratégias de pesquisa! 


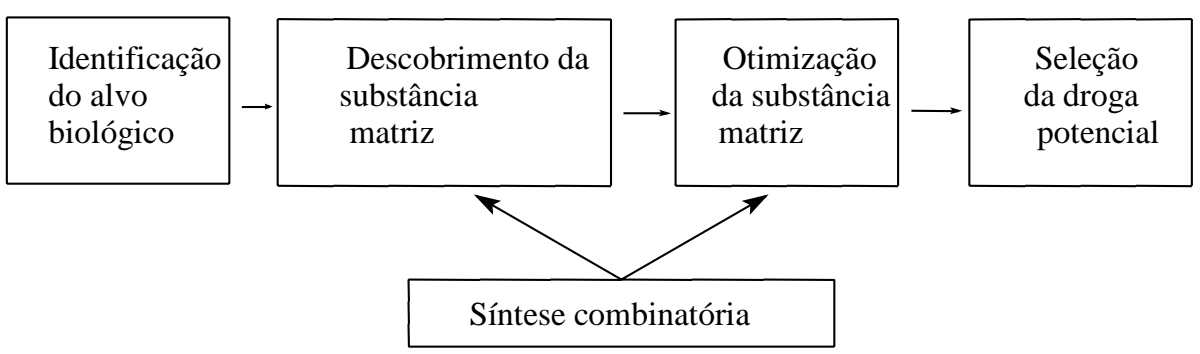

Figura 5. Impacto da síntese combinatória.

São várias as utilidades de produtos naturais: (i) suplementos alimentares, (ii) medicamentos, (iii) intermediários indústriais. Qualquer que seja sua aplicação há que se incluir uma questão de fundamental importância não apenas na conjuntura da rede de cooperação, mas principalmente no que diz respeito ao uso de NCEs em seres humanos, na agricultura, no meio-ambiente, que é a ética.

Os benefícios evidentes, tanto quanto para os competidores, são oriundos da capacidade instalada de pesquisa e das colaborações possíveis entre a academia e a indústria farmacêutica. A pesquisa pode ser realizada em vários laboratórios, inclusive distribuídos pelo mundo, desde que os benefícios de diferentes culturas levem à inovação nos processos de descobrimento de drogas ${ }^{51}$.

\section{CONCLUSÃO E PERSPECTIVAS}

Não há dúvidas da influência de produtos naturais no processo de descobrimento de novas drogas ${ }^{52}$. Entretanto, as diferenças ainda existentes na conjuntura nacional bem como aquelas inerentes à riqueza dos países desenvolvidos e à probreza dos países em desenvolvimento são responsáveis pelo estabelecimento dos níveis de pesquisa a realizar ${ }^{53}$. Políticas múltiplas são necessárias para que sejam estabelecidos caminhos a seguir, particularmente no que diz respeito a três categorias diferentes de fármacos que são conhecidas: os fármacos essenciais, os novos fármacos e aqueles ainda a desenvolver ${ }^{53}$.

Destarte, algumas medidas precisam ser implementadas para que a discussão apresentada neste artigo não fique apenas no campo das elucubrações daqueles que pensam em contribuir para o descobrimento e desenvolvimento de novas drogas:

1. Estabelecer colaborações entre universidades com suporte financeiro de indústrias farmacêuticas para a realização de ensaios biológicos em larga escala (automatizados) e também aqueles devido ao estudo mecanístico dos processos de interação droga-sistema biológico. Equipar e gerenciar inventários biológicos das espécies de plantas locais através de identificação taxonômica;

2. Mobilizar capital local para sustentar a bioprospeção em escala comercial quando o projeto for realizado;

3. Respeito aos povos indígenas e à sabedoria popular capazes de produzirem informações de interesse em produtos naturais, bem como à propriedade intelectual;

4. Implementar uma política nacional de pesquisadores em nível de pós-doutoramento para trabalhar nos projetos;

5. Estabelecer redes de cooperação de acordo com suas competências técnico-acadêmicas;

6. Estabelecer a capacidade empreendedora em negócios baseados em biotecnologia, em redes de cooperação;

7. Desenvolver a indústria farmacêutica nacional baseada em fitoterápicos.

\section{AGRADECIMENTOS}

Os autores agradecem às agências de financiamento $\mathrm{CNPq}$, FINEP, FAPESP e FAPEMIG. Também agradecem aos Profs. Quézia B. Cass e James Cosentino, da IOCD, pela realização do workshop Strategies in Drug Development from Natural Products, que contribuiu para a concretização do presente artigo.

\section{REFERÊNCIAS}

1. Gottlieb, O. R., Kaplan, M, A.; Borin, M. R.; Biodiversidade um Enfoque Quimio-biológico; Editora UERJ; Rio de Janeiro, RJ, 1996.

2. Wheelwrigh, E. G.: Medicinal Plants and their History; Dover Publications; New York, NY, 1974.

3. Vanhaelen, M.; J. Pharm. Belg. 1989, 44, 242.

4. Phillpson, J. D.; Anderson, L. A.; J. Ethnopharmacol. 1898, 25, 61 .

5. Reinbothe, C.; Diettrich, B.; Luckner, M.J.; Plant. Physiol. 1990, 137, 224.

6. Brito, N. R. S.; Tese de Doutorado, USP, São Paulo, SP, 1986.

7. Rosenthal, G. A.; Jansen, D. H.; Herbivores and Their Interaction with Secondary Metabolites; Academic Press; New York, 1979; p 3-160 e p 309-350.

8. Fleuretin, J.; Pelt, J-M.; La Recherche 1990, 21, 810.

9. Miller, R. W.; Powell, R. G.; Smith, C. R. Jr.; Arnold, E.; Clardy, J.; J. Org. Chem. 1981, 46, 1469.

10. Powell, R. G.; Miller, R. W.; Smith Jr., C. R.; J. Chem. Soc. Chem. Commun. 1979, 102.

11. Stinson, S. C.; Chem. Eng. News 1995, 9, 44.

12. Caldwell, J.; Modern Drug Discov. 1999, 7/8, 51.

13. Littlehales, C.; Anal. Chem. 1999, 71, 749.

14. Montanari, C. A.; Quim. Nova 1995, 18, 56.

15. (a) Leitão, A.; Montanari, C. A.; Donnici, C. L.; Quim. Nova 2000, 23, 178 (b) Ooms, F.; Curr. Med. Chem. 2000, 7, 141.

16. Stafford, A. M.; Pazoles, C. J.; Scott Siegel, S.; Yeh, Li-An.; Plant Cell Culture: a vehicle for Drug Discovery, In Advances in Drug Dicovery Techniques, John Willey \& Sons; New York; 1998.

17. Kniaz, D.; Modern Drug Discov. 2000, 5, 67.

18. IBC's Fourth International Simposium on Natural Drug Discovery \& Development: Novel Technologies, Diverse Sources \& Therapeutic Developments, June 15-16 1998, Annapolis, MD-USA.

19. Silverman, R. B., In The Organic Chemistry of Drug Design and Drug Action; Academic Press, Inc; San Diego, 1992.

20. (a) Cumming, J. N.; Ploypradith, P.; Posner, G. H.; Adv. Pharmacol. 1997, 37, 253. (b) Posner, G. H.; O'Dowd, H.; Ploypradith, P.; Cumming, J. N.; Xie, S.; Shapiro, T. A.; J.Med. Chem. 1998, 41, 2164.

21. White, R. E.; Annu. Rev. Pharmacol. 2000, 40, 133.

22. Cordell, G. A.; Shin, Y. G.; Pure Appl. Chem. 1999, 71, 1089.

23. Lanzov, V. A.; Mol. Genet. Metab. 1999, 68, 276.

24. Montanari, M.L.C.; Beezer, A.E.; Montanari, C.A.; Thermochim. Acta. 1999, 328, 91.

25. (a) Lima, P. C.; Lima, L. M.; da Silva, K. C. M.; Leda, P. H. O.; de Miranda, A. L. P.; Fraga, C. A. M.; Barreiro, E. J.; Eur. J. Med. Chem. 2000, 35, 187. (b) Clark, R. D.; Ferguson, A. M.; Cramer, R. D.; Perspect. Drug Discov. 1998, 9-11, 213. (c) Patani, G. A.; LaVoie, E. J.; Chem. Rev. 1996, 96, 3147. 
26. Montanari, C. A.; Tute, M. S.; Beezer, A. E.; Mitchell, J. C.; .J. Comput.-Aid. Mol. Des. 1996, 10, 67.

27. (a) Meyer, E. F.; Swanson, S. M.; Williams, J. A.; Pharmacol. Therapeut. 2000, 85, 113. (b) Kuntz, I. D.; Science 1992, 257, 1078 (c) Fairlie, D. P.; Tyndall, J. D. A.; Reid, R. C.; Wong, A. K.; Abbenante, G.; Scanlon, M. J.; March, D. R.; Bergman, D. A.; Chai, C. L. L.; Burkett, B. A.; J. Med. Chem. 2000, 43, 1271.

28. Van de Waterbeem, H.; Testa, B.; Folkers, G.; ComputerAssisted Lead Finding and Optimization. Current Tools for Medicinal Chemistry. Wiley-VCH, Weinheim, 1997

29. Hopfinger, A. J.; Wang, S.; Tokarski, J. S.; Jin, B. Q.; Albuquerque, M.; Madhav, P. J.; Duraiswami, C.; J. Am. Chem. Soc. 1997, 119, 10509.

30. Gschwend, D. A.; Good, A. C.; Kuntz, I. D.; J. Mol. Recognit. 1996, 9, 175.

31. Sandak, B.; Wolfson, H. J.; Nussinov, R.; Prot.Struct. Funct. Gen. 1998, 32, 159.

32. Edgcomb, S. P.; Murphy, K. P.; Cur. Opin. Biotechnol. 2000, 11, 62.

33. Fastrez, J.; Mol. Biotechnol. 1997, 7, 37.

34. Gebhardt, R.; Planta Med. 2000, 66, 99.

35. (a) Watt, A. P.; Morrison, D.; Evans, D. C.; Drug Discov. Today 2000, 5, 17. (b) Smith, D. A.; Van de Waterbeemd, H.; Curr. Opin. Chem. Biol. 1999, 3, 373.

36. (a) Lipinski, C. A.; Lombardo, F.; Dominy, B. W.; Feeney, P. J.; Adv. Drug Del. Rev. 1997, 23, 3. (b) Ajay, Walters, W. P.; Murcko, M. A.; J. Med. Chem. 1998, 41, 3314. (c) Sadowski, J.; Kubinyi, H.; J. Med. Chem. 1998, 41,3325 .

37. TSAR, versão 3.21, Oxoford Molecular, Ltd., Oxford, U.K..

38. Hajduk, P. J.; Gerfin, T.; Boehlen, J. M.; Haberli, M.; Marek, D.; Fesik, S. W.; J. Med. Chem. 1999, 42, 2315.

39. Bohm, H. J.; J. Comput. Aid. Mol. Des. 1998, 12, 309.
40. Kuntz, I. D.; Blaney, J. M.; Oatley, S. J.; Langridge, R.; Ferrin, T. E.; J. Mol. Biol.1982, 161, 269.

41. Goodford, P.J.; J. Med. Chem. 1985, $28,849$.

42. (a) Moon, J. B.; Howe, W. J.; Proteins 1991, 11, 314. (b) Moon, J. B.; Howe, W. J.; Tetrahedron Comput. Methodol. 1990, 3, 681.

43. (a) Kubinyi, H.; $3 D$ QSAR in Drug Design. Theory, Methods and Applications, ESCOM, Leiden, 1993 (b) Kubinyi, H.; Folker, G.; Martin Y. C., 3D QSAR in Drug Design. Ligand-Protein Interactions and Molecular Similarity, Vol. 2, KLUWER/ESCOM, Dordrecht/Boston/ London, 1998 (c) Kubinyi, H.; Folker, G.; Martin Y. C.; 3D QSAR in Drug Design. Recent Advances, Vol. 3, KLUWER/ESCOM, Dordrecht/Boston/London, 1998.

44. (a) Referência (29). (b) Hopfinger, A. J.; Vankatarangan, P.; Tseng, Y. F.; Wang, S.; Duca, J. S.; Internet J. Chem. 2000, 3, U23.

45. Montanari, C. A.; Tute, M. S.; Quant. Struct-Act. Rel. 1997, 16, 480.

46. Cruciani, G.; Clementi, S.; Pastor, M.; Perspect. Drug Discov. 1998, 12,71 .

47. Frank, R.; Gruska, A.; In Methods and Principles in Medicinal Chemistry. Chemometric Methods in Molecular Design. Van de Waterbeemd, H., Ed.. (a) Principal Components and Factor Analysis, p 113-163. (b) SIMCA Pattern Recognition and Classification, p 179-193. VCH; Weinheim, 1995.

48. Kubinyi, H.; Drug Disc. Develop. 1998, 1, 4.

49. Hansch, C.; Accounts Chem. Res. 1993, 26, 147.

50. Xiang, X. D.; Schultz, P. G.; Physica 1997, 282, 428.

51. Turner, D. M. J.; Ethnopharmacol. 1996, 51, 39.

52. Newman, D. J.; Cragg, G. M.; Snader, K. M.; Nat. Prod. Rep. 2000, 17, 215.

53. Reich, M. R.; Science 2000, 287,1979. 